\title{
Influence of mineral phase in mineralization of a biocomposite containing chitosan, demineralized bone matrix and bone ash- in vitro study
}

\author{
KRITHIGA GUNASEKARAN, SANTHOSH KUMAR BASKAR, DIVYA SAPPHIRE MOHAN \\ and THOTAPALLI P SASTRY* \\ Bio-Products Laboratory, Central Leather Research Institute, Adyar, Chennai 600 020, India
}

MS received 4 October 2012

\begin{abstract}
A resorbable composite which acts as a active barrier in guided bone regeneration was fabricated using chitosan, demineralized bone matrix and bone ash. Its potential to form bone like apatite in simulated body fluid was assessed in this study. The mechanical strength of these composites was correlated with bone ash ratios and composites with better tensile strength were studied for their acellular bioactivity by incubating in simulated body fluid for 21 days. Composites without bone ash did not show acellular bioactivity which was confirmed by thermogravimetric analysis. In case of biocomposites with bone ash, there was an increase in residual weight indicating the mineralization of the composite. The composite containing bone ash has shown the peaks related to phosphate vibrations in its Fourier-transform infrared spectrum. Scanning micrographs revealed formation of apatite like crystals on its surface. $\mathrm{Ca} / \mathrm{P}$ ratio was found to be 1.7 which is nearer to that of natural bone. Thus, prepared composites can be used as resorbable biocomposite in maxillofacial and oral defects.
\end{abstract}

Keywords. Biomineralization; chitosan; simulated body fluid; bioactivity; biocomposite.

\section{Introduction}

Bone healing is a phenomenon which requires ideal materials and techniques to accomplish. Guided bone regeneration (GBR) is one of the ideal techniques which help in bone regeneration inside the secluded spaces of bone defects without the intervention of fibrous tissues. This is achieved by using composite as a barrier material (Schenk et al 1994; Piattelli et al 1996). Other forms of GBR biomaterials are meshes, plates, screws or nodes that induce bone growth along the surfaces and inside the biomaterial. A wide variety of polymers including both synthetic and natural, ceramics, bioactive glasses and composites are used in GBR (Jansen et al 1995; Ma et al 2003; Van Leeuwen et al 2012). Expandable polytetrafluoroethylene (e-PTFE) polymer is widely used bioactive composite, but it requires removal surgery because of its bioinert property (Simon et al 1994). Resorabable composites with good biocompatibility, bioactivity, high flexibility, with required mechanical strength will be able to meet the requirements of GBR.

As resorbable composites, materials like collagen, chitosan, synthetic polymers like poly-lactic acid (PLA), copolymers of PLA, poly-glycolic acid (PGA), PLLA and

*Author for correspondence (sastrytp@ hotmail.com) bioceramics like hydroxyapatite, $\beta$-tricalcium phosphate $(\beta$-TCP) and biphasic calcium phosphate (BCP) have been studied (Kikuchi et al 2004; Jeon et al 2007; Lee et al 2010). Chitosan, a biopolymer has biocompatibility, biodegradability, antimicrobial activity, wound healing property, bone bonding ability and can be prepared economically (Qi et al 2004; Di Martino et al 2005). Demineralized bone matrix (DBM), organic part of bone, consists of all essential growth factors and proteins for faster bone formation when placed in bone defects (Caplanis et al 1997). Hydroxyapatite which has wide clinical applications resembles the mineral phase of bone. It is osteoconductive, biocompatible and has slow degradation rate compared to other calcium phosphates (Deepak et al 2005). Naturally prepared hydroxyapatite showed good biocompatibility and osteoconductivity compared to synthetic hydroxyapatite (Mostafa 2005). Bioactive materials have the capacity to form hydroxyl-carbonate apatite layer, resembling mineral phase of bone structurally and chemically on their surface which enables the bonding between the material and bone (Ahmet et al 2010). In recent years, in vivo osteointegration of the biomaterial was determined by bone forming ability, i.e. bioactivity when placed in simulated body fluid, SBF. Simulated body fluid was acellular fluid which contains all the ions and their concentrations as that of blood (Kokubo et al 1990). 
In this present study, a resorbable biocomposite composite was fabricated using chitosan as a continuous phase containing DBM with different amounts of bone ash. The influence of mineral phase on the nucleation of bone like apatite was studied by incubating the resorbable composite in the SBF.

\section{Experimental}

\subsection{Materials}

Chitosan (72-85\% deacetylation) was obtained from Sigma, Aldrich, India. Demineralized bone matrix (DBM) was prepared by collecting the bovine tibial bones from nearby slaughter house, washed thoroughly in distilled water and defatted using chloroform-acetone in the ratio of $1: 3$. The defatted bones were cut into $2^{\prime \prime} \times 2^{\prime \prime}$ pieces and demineralized using $2 \mathrm{~N} \mathrm{HCI}$ for 7 days at $4{ }^{\circ} \mathrm{C}$. The $\mathrm{pH}$ of demineralized pieces were brought to 7 , crushed and made into paste. The obtained paste was lyophilized and stored at $4{ }^{\circ} \mathrm{C}$ till further use. For bone ash (BA), $2^{\prime \prime} \times 2^{\prime \prime}$ bone pieces were incinerated at $900{ }^{\circ} \mathrm{C}$ for $5 \mathrm{~h}$. Then cooled, crushed and sieved to a particle size of 75$750 \mu \mathrm{m}$ and the resulting white powder was further used as such. Other chemicals used were of analytical grade. Simulated body fluid (SBF) was prepared by dissolving analytical grade $\mathrm{NaCl}, \mathrm{NaHCO}_{3}, \mathrm{KCl}, \mathrm{K}_{2} \mathrm{HPO}_{4} \cdot 3 \mathrm{H}_{2} \mathrm{O}$, $\mathrm{MgCl} \cdot 6 \mathrm{H}_{2} \mathrm{O}, \mathrm{CaCl}_{2}$ and $\mathrm{Na}_{2} \mathrm{SO}_{4}$ in deionized water. The solution was buffered at $\mathrm{pH} 7.4$ with tris(hydroxylmethyl aminomethane $\left(\left(\mathrm{CH}_{2} \mathrm{OH}\right)_{3} \mathrm{CNH}_{2}\right)$ and $1 \mathrm{M}$ hydrochloric acid $(\mathrm{HCl})$ at $36.5^{\circ} \mathrm{C}$. The solution was stored at $4{ }^{\circ} \mathrm{C}$.

\subsection{Preparation of biocomposite composites}

DBM powder $(2 \mathrm{w} / \mathrm{v} \%)$ was mixed with $2 \%$ chitosan solution $(50 \mathrm{ml})$ and sonicated for half an hour and poured into polyethylene trays with measurements $9 \times 9 \mathrm{~cm}$ and dried. The dried composites were treated with $0.5 \%$ gluteraldehyde $(25 \%)$ for $3 \mathrm{~h}$ at $30{ }^{\circ} \mathrm{C}$. The cross-linked sheet was thoroughly washed with doubleddistilled water and dried in an oven at $40^{\circ} \mathrm{C}$. The resulting biocomposites were denoted as CD.

\subsection{Incorporation of $B A$ into $C D(C D B A)$}

Different amounts of bone ash (2, 2.5, 3 and $3.5 \mathrm{w} / \mathrm{v} \%)$ was added to the chitosan and DBM mixture $(2 \mathrm{~g}$ DBM and $2 \%$ chitosan) and the resultant mixture was sonicated for $1 \mathrm{~h}$ and poured into polyethylene trays with measurements $9 \times 9 \mathrm{~cm}$ and dried at room temperature $\left(30 \pm 5{ }^{\circ} \mathrm{C}\right)$. The details of weight by volume ratios are given in table 1 .

\subsection{In vitro biomineralization test}

The biocomposites with better tensile strength was further studied by incubating in simulated body fluid (SBF) at $37^{\circ} \mathrm{C}$ for 21 days. After 21 days, the biocomposites were taken out and rinsed with demineralized water and dried at $50{ }^{\circ} \mathrm{C}$. The dried samples were characterized by FTIR, TGA, SEM and EDX.

\subsection{Characterization of biocomposite composites}

Tensile strength of the biocomposites was measured using the universal testing machine (INSTRON model 1405). The IR spectra of the samples prepared were recorded in the $4000-500 \mathrm{~cm}^{-1}$ range using Nicolet Impact 400 Fourier-transform infrared spectrophotometer using $\mathrm{KBr}$ pellet containing $1-2 \mathrm{mg}$ of the sample. The TGA of the biocomposites prepared was carried out using a Seiko SSC $5200 \mathrm{H}$ in nitrogen atmosphere $(80 \mathrm{~mL} / \mathrm{min})$ at a heating rate of $10^{\circ} \mathrm{C} / \mathrm{min}$. Primary weight loss of these materials as a function of temperature was recorded using this study. Dried samples were coated with solid ions using an ion coater (fisons sputter coater) under the following conditions: $0 \cdot 1$ Torr pressure, 200 MA current and $70 \mathrm{~s}$ coating time. Surface structure was visualized by scanning electron microscope (SEM model-LEICA stereoscan 440) using a $15 \mathrm{kV}$ accelerating voltage. For EDX analysis, samples were mounted on holders and $6 \mathrm{~nm}$ sputter-coated with carbon by means of a MED 020 sputter device (Bal-Tec). In a Philips scanning electron microscope (Philips, Eindhoven, the Netherlands), EDX analyses were performed at 5 and $10 \mathrm{kV}$.

\section{Results and discussion}

The tensile strength of CD and CDBA (1-4) were given in table 1. In CDBA samples, there was increase in tensile strength up to $2.5(\mathrm{w} / \mathrm{v} \%) \mathrm{BA}$ and strength decreases with increase in BA percentage. The higher tensile strength of CDBA compared to CD can be attributed to the natural bonding between DBM and BA. With the increase in $\mathrm{w} / \mathrm{v}$ percentage of $\mathrm{BA}$, tensile strength decreases as the inorganic particles serve as a point of origin of failure (Lee et al 2009).

The samples CD and CDBA2 which showed better tensile strength were tested for in vitro bioactivity. Figure 1(a-d) shows the FT-IR spectrum of CD and CDBA2 before and after incubation in SBF for 21 days. The characteristic collagen bands are observed as amides I and II at 1648 and $1557 \mathrm{~cm}^{-1}$, respectively in the sample before treatment in SBF (figure 1a). There is a shift in these peaks to 1641 and $1542 \mathrm{~cm}^{-1}$ in the IR spectrum of CD after treatment in SBF (figure 1b). Similarly, the hydroxyl group representing at $1034 \mathrm{~cm}^{-1}$ before treatment of sample in SBF is shifted to $1023 \mathrm{~cm}^{-1}$ after 
Table 1. Tensile strength of biocomposite.

\begin{tabular}{lccccc}
\hline $\begin{array}{l}\text { Sl. } \\
\text { No. }\end{array}$ & $\begin{array}{c}\text { Sample } \\
\text { ID }\end{array}$ & $\begin{array}{c}\text { Chitosan } \\
\text { (w/v\%) }\end{array}$ & $\begin{array}{c}\text { Demineralized } \\
\text { bone matrix } \\
\text { (w/v\%) }\end{array}$ & $\begin{array}{c}\text { Bone ash } \\
\text { (w/v\%) }\end{array}$ & $\begin{array}{c}\text { Tensile } \\
\text { strength } \\
\text { (MPa) }\end{array}$ \\
\hline 1 & CD & 2 & $2 \cdot 5$ & - & $3 \cdot 38 \pm 0 \cdot 3$ \\
2 & CDBA1 & 2 & $2 \cdot 5$ & $2 \cdot 0$ & $4 \cdot 09 \pm 0 \cdot 5$ \\
3 & CDBA2 & 2 & $2 \cdot 5$ & $2 \cdot 5$ & $4 \cdot 97 \pm 0 \cdot 2$ \\
4 & CDBA3 & 2 & $2 \cdot 5$ & $3 \cdot 0$ & $3 \cdot 86 \pm 0 \cdot 6$ \\
5 & CDBA4 & 2 & $2 \cdot 5$ & $3 \cdot 5$ & $2 \cdot 69 \pm 0 \cdot 2$ \\
\hline
\end{tabular}

Mean and SD values are calculated for five different samples.

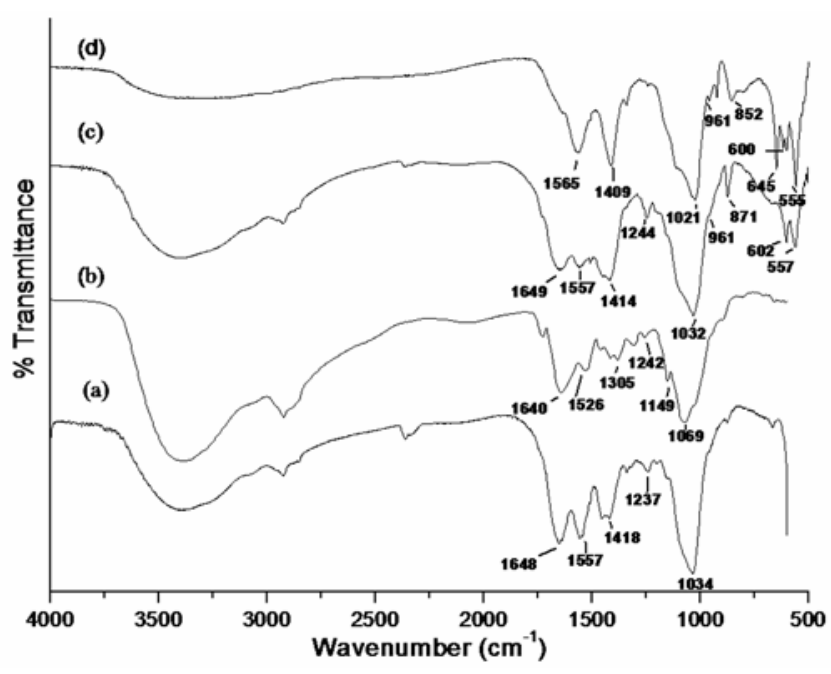

Figure 1. FT-IR spectrum of (a) $\mathrm{CD},(\mathbf{b}) \mathrm{CD}$ after incubation in SBF, (c) CDBA2 and (d) CDBA2 after incubation in SBF.

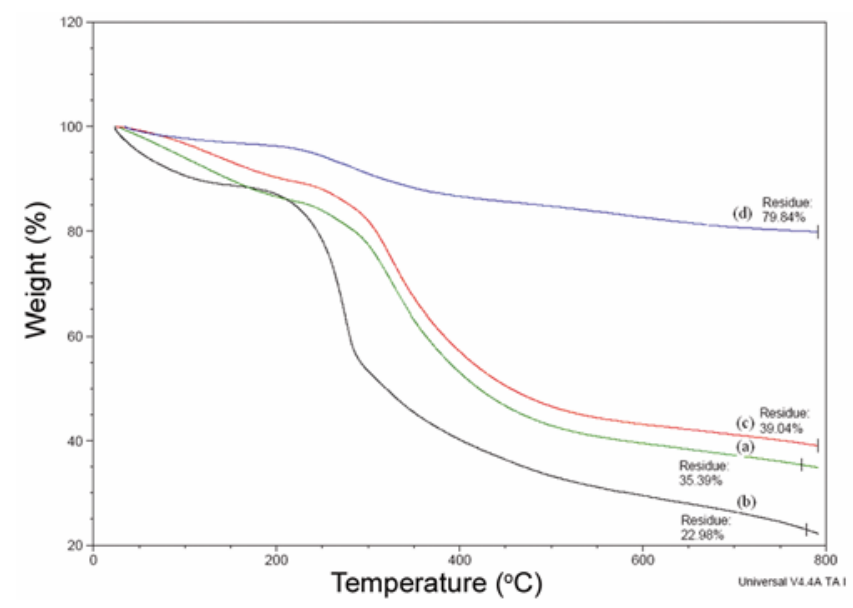

Figure 2. Thermograms of (a) $\mathrm{CD}$, (b) $\mathrm{CD}$ after incubation in $\mathrm{SBF}$, (c) $\mathrm{CDBA} 2$ and (d) CDBA2 after incubation in SBF (colour in web only).

treatment. The slight shift may be due to the degradation in SBF. However, no stretching $v_{1}$ vibration band was observed at $961 \mathrm{~cm}^{-1}$. In CDBA2 (figure 1c) before incubation in SBF, the phosphate stretching band as slight bend was observed at $961 \mathrm{~cm}^{-1}$. However, a marked shoulder at $961 \mathrm{~cm}^{-1}$ was observed in the sample after incubation in SBF (figure 1d). The carboxyl groups and hydroxyl groups in CD sample did not induce any apatite formation. The presence of $\mathrm{Ca}$ ions, $\mathrm{Si}-\mathrm{OH}$ and $\mathrm{Ti}-\mathrm{OH}$ groups are needed for the nucleation of apatite in SBF, which was confirmed by the presence of marked peaks in CDBA2 biocomposite after incubation in $\mathrm{SBF}$.

Thermogravimatric analysis was done to confirm the apatite formation by the increased residual weight after incubation in SBF. The thermogravimetric analysis of sample CD (figure 2a) has shown two step weight loss between 238 and $450{ }^{\circ} \mathrm{C}$. The first weight loss at 238$290{ }^{\circ} \mathrm{C}$ may be due to the $5 \%$ denaturation of protein and second loss of $33 \%$ at $290-450{ }^{\circ} \mathrm{C}$, due to the decomposition of denatured products. Residue of $35 \%$ was observed at $800{ }^{\circ} \mathrm{C}$. In sample $\mathrm{CD}$, after treatment in $\mathrm{SBF}$ as shown in figure 2(b), two step weight loss was observed at 210 $350{ }^{\circ} \mathrm{C}$. However, $22 \%$ residue was observed at $800{ }^{\circ} \mathrm{C}$. This result shows the degradation of biomaterial treated in the SBF and there is no indication of ossification. The TGA profile of before and after incubating in SBF are shown in figure 2(c) and (d), respectively. In CDBA2 before incubation, $39 \%$ residue was observed at $800{ }^{\circ} \mathrm{C}$, whereas approximately $80 \%$ residue was observed in CDBA2 after incubation at similar temperature. This is an indication for the ossification of biomaterial treated in SBF.

Based on the results, SEM studies were done only for sample CDBA2 before and after SBF. In CDBA2 before incubation (figures $3 \mathrm{a}$ and $\mathrm{b}$ ), the inorganic crystals are seen as embedded particles on the CD matrix. After incubation in SBF, the surface of CDBA2 revealed the formation of apatite layer by showing spherulite at lower magnification and petal like arrangements at higher magnification (figures 3c and d) (Neo et al 1993). The EDAX graphs detected the elemental analysis, which indicates the presence of calcium and phosphorous compounds in the given sample. The ratio between calcium and phosphorous were observed before and after treatment. Before treatment (figure 4a), the ratio was around 3.7 and after treatment, it is 1.7 (figure $4 \mathrm{~d}$ ). The presence of $\mathrm{Ca}$ and $\mathrm{P}$ in EDX shows the residual weight gain 


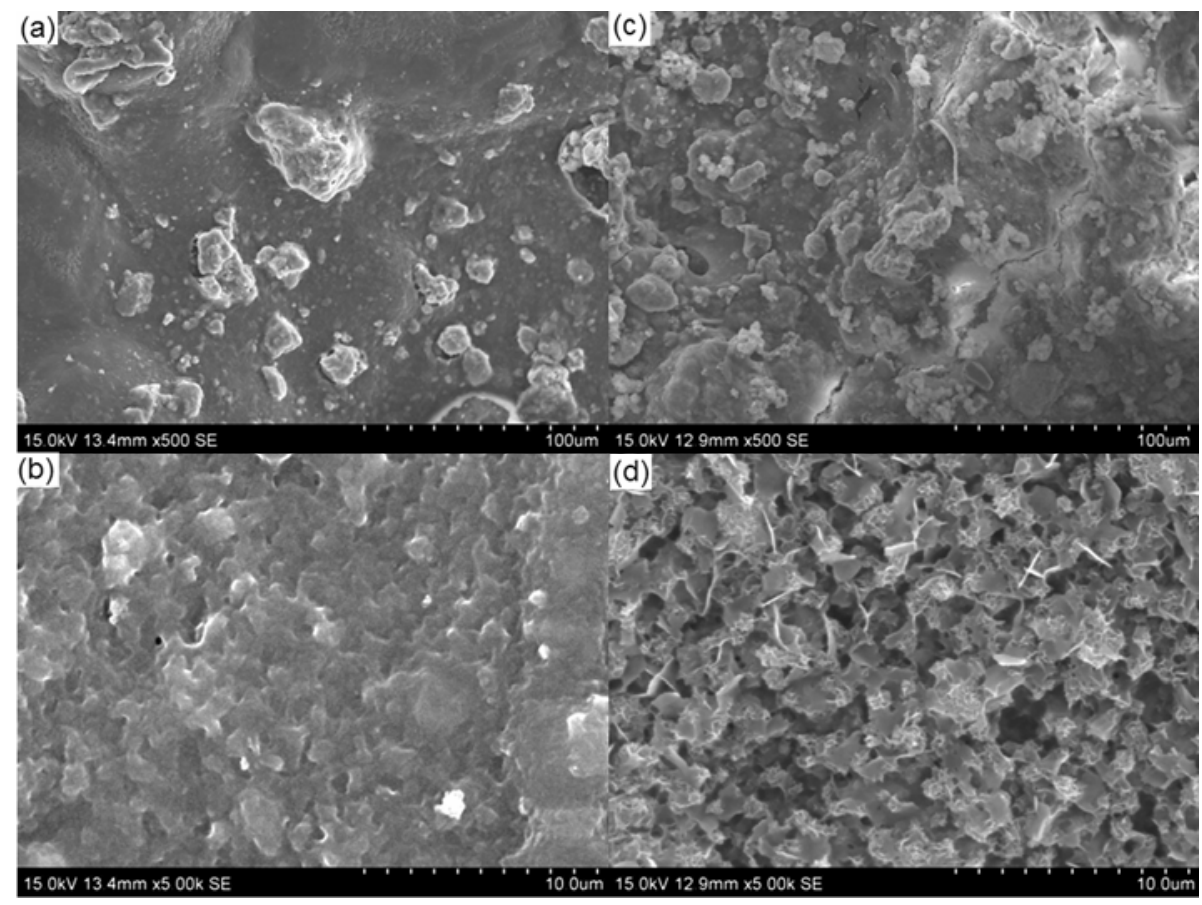

Figure 3. SEM micrographs of (a) CDBA2 at $500 \times$, (b) $\mathrm{CDBA} 2$ at $5000 \times$, (c) $\mathrm{CDBA} 2$ after incubation in SBF at $500 \times$ and (d) CDBA2 after incubation in SBF at $5000 \times$.
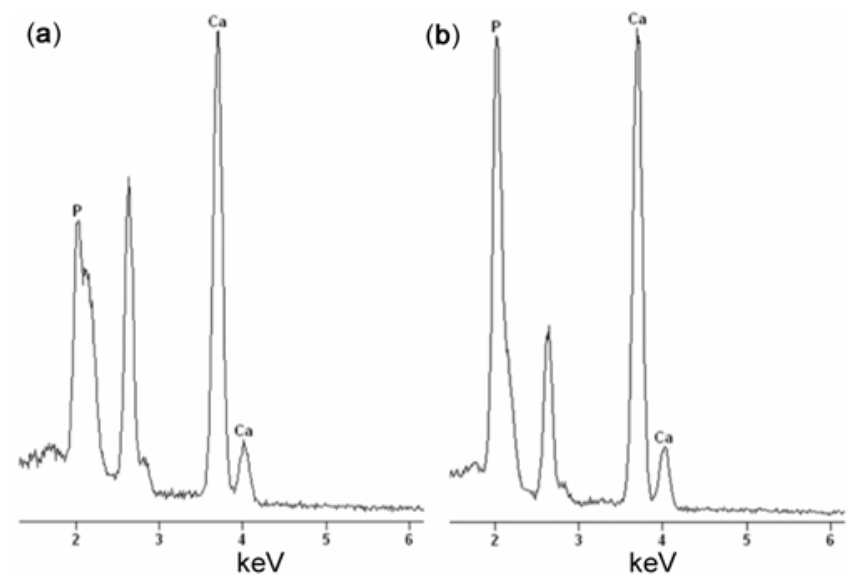

Figure 4. EDX graphs of (a) $\mathrm{CDBA} 2$ and (b) $\mathrm{CDBA} 2$ after incubation in SBF.

after incubation was indeed due to the apatite. The high $\mathrm{Ca} / \mathrm{P}$ ratio of $\mathrm{CDBA} 2$ before incubation in $\mathrm{SBF}$ was because of the $\mathrm{Ca} / \mathrm{P}$ ratio of bone ash which changes with age, diet of the bovine and also the sintering temperature (Toque et al 2007). $\mathrm{Ca} / \mathrm{P}$ ratio of the apatite formed was found to be 1.7 , which correlates with ratio of hydroxyapatite.

\section{Conclusions}

In vitro bioactivity test of biocomposite, CDBA2 showed bone-like apatite formation which was confirmed by thermogravimetric and SEM analyses. To further confirm the results obtained in this study, in vivo experiments in rats are under progress.

\section{References}

Ahmet P, Mithat Y, Erdal C, Sevil S and Cuneyt Tas A 2010 Acta Biomaterialia 62282

Caplanis N, Sigurdsson T J, Rohrer M D and Wikesjo U M 1997 Int. J. Oral. Maxillofac. Implant 12634

Deepak K, Patnayak P, Divya S, Upadhyay R C, Prasad B T R and Rama Mohan T R 2005 Trends. Biomater. Artif. Organs 1887

Di Martino A, Sittinger M and Risbud M V 2005 Biomaterials 265983

Toque J A, Herliansyah M K, Hamdi M, Ide-Ektessabi A and Wildan M W 2007 IFMBE Proceedings 15152

Jansen J A, De Ruijter J E, Jansen P T M and Paquay Y G C J 1995 Biomaterials 16819

Jeon O, Song S J, Kang S W, Putnam A J and Kim B S 2007 Biomaterials 282763

Kikuchi M et al 2004 Biomaterials 255979

Kokubo T, Kushitani H, Sakka S, Kitsugi T and Yamamuro T 1990 J. Biomed. Mater. Res. 24721

Lee E J, Shin D S, Kim H E, Kim H W, Koh Y H and Jang J H 2009 Biomaterials 30743

Lee E J, Teng S H, Jang T S, Wang P, Yook S W, Kim H E and Koh Y H 2010 Acta Biomaterialia 63557

Ma L, Gao C, Mao Z, Zhou J, Shen J, Hu X and Han C 2003 Biomaterials 244833 
Mostafa N Y 2005 Mater. Chem. Phys. 94333

Neo M, Nakamura T, Ohtsuki C, Kokubo T and Yamamuro T 1993 J. Biomed. Mater. Res. 27999

Piattelli A, Scarano A, Russo P and Matarasso S 1996 Biomaterials 17791

Qi L X Z, Jiang X, Hu C and Zou X 2004 Carbohydr. Res. 339 2693
Schenk R K, Buser D, Hardwick W R and Dahlin C 1994 Int. J. Oral. Maxillofac. Implants 913

Simon M, Baldoni M, Rossi P and Zaffe D 1994 Int. J. Periodont. Restorative. Dent. 14166

Van Leeuwen A C, Huddleston Slater J J R, Gielkens P F M, De Jong J R, Grijpma D W and Bos R R M 2012 Acta Biomaterialia 81422 